\title{
Carbon Dioxide and Exsanguination
} Euthanasia

National Cancer Institute

\section{Source}

National Cancer Institute. Carbon Dioxide and Exsanguination Euthanasia. NCI

Thesaurus. Code C106507.

A method of euthanasia whereby a subject inhales carbon dioxide until asphyxiation occurs and then the body is immediately drained of blood. 